Article

\title{
As Symbol as That: Inconsistencies in Symbol Systems of Alleles in Textbooks, and Students' Justifications for Them
}

\author{
Gur A. Livni-Alcasid ${ }^{\dagger}$, Michal Haskel-Ittah *,+ ${ }^{*}$ and Anat Yarden \\ Department of Science Teaching, Weizmann Institute of Science, Rehovot 76100, Israel; \\ gurarie.livnialcasid@weizmann.ac.il (G.A.L.-A.); Anat.Yarden@weizmann.ac.il (A.Y.) \\ * Correspondence: Haskel@weizmann.ac.il \\ + These authors contributed equally (co-first author).
}

Received: 30 June 2018; Accepted: 1 August 2018; Published: 2 August 2018

\begin{abstract}
In genetics education, symbols are used for alleles to visualize them and to explain probabilities of progeny and inheritance paradigms. In this study, we identified symbol systems used in genetics textbooks and the justifications provided for changes in the symbol systems. Moreover, we wanted to understand how students justify the use of different symbol systems when solving genetics problems. We analyzed eight textbooks from three different countries worldwide. We then presented a genetics problem to eight 9th-grade students and probed their justifications for the use of different symbol systems. Our findings showed that there is no one conventional symbol system in textbooks; instead, symbol systems are altered along and within textbooks according to the genetic context. More importantly, this alteration is not accompanied by any explicit explanation for the alteration. Student interviews revealed that some students were able to identify the genetic context of each symbol system, whereas others, who were unable to do so, provided justifications based on different non-genetics-related reasons. We discuss the implications of our analysis for how multiple symbol systems should be presented in textbooks, and how they should be introduced in the classroom.
\end{abstract}

Keywords: symbol; genetics; visual representation; gene

\section{Introduction}

External representations are used by scientists to communicate with one another and with the non-scientist population. Therefore, the meaning that is embodied in a representation by its creator should be understood by all those who perceive it [1]. Furthermore, using external representations in a flexible manner allows scientists to manipulate those representations, thus creating a working model that can be updated when new experimental results are obtained or a new understanding is reached [2]. Thus, it seems that the power of representations is rooted in the ability to transform them, an ability that is reserved for those who can comprehend the semiotic system.

We focus in this article on visual representations, i.e., an external representation perceived by the visual senses, which is the result of an attempt to communicate a mental model [1]. It has been claimed that just as visual representations are important to the work of scientists and the development of science, they are also important in teaching the subject $[3,4]$. However, students at various ages experience difficulties in interpreting and using scientific representations $[5,6]$. They often misinterpret them, for example, they interpret an arrow in a scientific representation as a movement instead of a process or vice versa [7]. In addition, they sometimes think that a diagram representing a structure actually represents a complex process [8], and they often apply the subscript of an element in a chemical formula to the following element rather than the preceding one [5]. 
Fluent performance in the transformation of visual representations has been described as requiring and demonstrating meta-visualization, namely the ability to acquire, monitor, integrate and extend learning that involves both internal and external representations [9]. Furthermore, this ability can foster the idea that distinct representational levels of scientific knowledge exist [3]. This means that the ability to use visual representations is supported by knowledge of the nature of visual representations and by metacognitive skills.

Visual representations in science can be organized in various ways. One method of organization, born out of the need to identify and address students' challenges in the science classroom, is Johnstone's [10] distinction between three organizational levels. The first level is at the macroscopic one, that of the phenomenon being studied, as it is directly perceived. The second is at the submicroscopic level, a representation of those entities that are thought to underlie the properties being displayed. The third is the symbolic level, the representation of the identities of entities. Biology is often addressed as unique in that there are four levels of representations: the macroscopic (visible biological structures), the microscopic (cellular level), the submicroscopic (molecular level) and the symbolic (symbols, formulas, pathways, etc.; [11]).

At each of these levels, the same object or process can be represented by various types of representations (e.g., graph, table, chart, symbol or formula). In some cases, these representations complete or constrain the interpretation of their represented object or process [12]. While the literature usually refers to the ability (or inability) of learners to translate information from one type of representation to another $[3,5,9,12]$, it could just as well be argued that the translation and manipulation of representations among the same types of representations should be performed and mastered by students. As an example, Gilbert [9] points out the intellectual demands and confusion that can emerge from using several symbol systems in the classroom, such as zinc + hydrochloric acid, $\mathrm{Zn}+\mathrm{HCl}$, and $\mathrm{Zn}_{(\mathrm{s})}+\mathrm{H}^{+}{ }_{(\mathrm{aq})}+\mathrm{Cl}^{-}{ }_{(\mathrm{aq})}$. While these are all visual representations of the symbolic type, each of them follows its own code, compelling the student to learn how to translate one into the other and when to use each of them.

As demonstrated above, one type of visual representation is symbols. However, while representations at the macroscopic, microscopic and submicroscopic level represent the real phenomenon on different scales, the symbolic level is a representation using formulas, equations, and diagrams. This usually makes symbols less depictive and more reliant on means of convention, rather than visual similarities. Thus, these symbols are only understood when the observer is familiar with the objects and the convention underlying the symbolic representation. This foundation might lead to a construction of an internal mental representation of the content described by the symbol [13-15].

As in the translation and manipulation of one type of representation to a different type of representation, the translation and manipulation of one symbol to another can be viewed as both a prerequisite for understanding the symbol and a way to establish the learners' understanding of that symbol's interpretation. An example of this can be seen in elementary-school students' difficulties in translating fractions to decimals and vice versa $[16,17]$. As we illustrate in this article, the translation of information between the same types of representations cannot be considered too simple a task for the novice high-school biology student.

In biology, symbols of alleles are used by experts to depict the genetic combination of a certain phenotype or to calculate, using a Punnett square, the progeny probabilities of a certain cross. In accordance with the three levels of external representations, the macroscopic level in this case is the representation of phenotypes-the appearance and disappearance of traits in a given organism. Hidden from the learner's eyes and quite abstract for the novice high-school biology student [18-20] are both the microscopic and submicroscopic levels. According to Marbach-Ad and Stavy [11], the microscopic level is the representation of alleles, whereas the submicroscopic level is the representation of DNA. The fourth level is the symbolic level of alleles, used to depict the genetic combinations in the individual with letters, and termed genotype. 
Studies have shown that students are able to apply algorithms and use allelic symbols to solve problems in classical genetics [21]. However, they have difficulty interpreting these allelic symbols and referring them to biological entities and processes [21,22]. These obstacles in understanding and using symbolic representations might well be expected, as the difficulties are obviously greater in domains in which the represented objects or processes are not clear to the learner. Many difficulties have been recorded in understanding the concept of genes and their different versions, termed alleles $[11,19,20,23,24]$. Alleles, in general, have been shown to be a challenging concept in genetics, as students seem to confuse between the terms 'allele', 'gene' and 'chromosome' $[25,26]$. Even more fundamental is students' inability to distinguish between a gene (a DNA sequence) and the genetic information encoded by that gene (which determines the precise nature of the gene product). Without this understanding, the whole concept of alleles is meaningless [27]. In addition, when students try to explain the progeny probabilities for a specific cross, they use alleles and their symbols in their explanations, but cannot explain the underlying biological processes in which these alleles participate [22].

While a vague understanding of the concepts of genes and alleles is an obstacle to the use of their symbolic representations, we have postulated that another variable affects the misuse of these symbols. As the semiotic representation is crucial for the manipulation of allele symbols (e.g., Punnet squares), the symbol must not be confused with the true object that it represents, i.e., the allele [2]. This, claims Duval [2], is a cognitive conflict for the learner, especially when shifting from one representation system to another. Therefore, changing from one symbol system of alleles to another might lead to confusion between alleles and their representations, especially when students have no access to the concept of alleles.

Curiously, this is exactly the case in genetics education. As an object, the allele is inaccessible to the student. In addition, while working with genetics textbooks, we noted that alleles are represented by several sets of conventions, which we term symbol systems. By this term, we mean a set of conventions that represent the method by which objects are represented by symbols. For example, in the Aa symbol system, the set of conventions includes using a consistent letter for the gene, and denoting the dominant allele by an uppercase letter and the recessive allele by a lowercase one. On the other hand, in the $\mathrm{A}^{1} \mathrm{~A}^{2}$ system, the set of conventions includes using a consistent letter for the gene, and denoting each different allele with a different superscript number.

We wondered whether these different symbol systems are used in the same manner worldwide, and why these various systems are used. While many studies in genetics education have emphasized the difficulties in connecting a macroscopic phenomenon with the microscopic and submicroscopic levels $[11,20]$, less attention has been paid to difficulties in understanding how the symbolic level and symbol system represent the other organizational levels. In this study, we focus on this latter aspect.

The significance of multiple symbol systems is apparent when reviewing studies in mathematics education. According to Duval [2], symbols in mathematics allow for the substitution of one sign with another, thus enabling the manipulation of representations and the transformation of symbols across a set of symbols. It might be argued that experts in mathematics can flexibly turn one symbol into another, allowing them to demonstrate their grasp of the mathematical objects. This is not the case for novices, who may encounter many difficulties in understanding and justifying the use of a specific symbol in some cases, but not in others $[16,17]$.

For students to be able to use representations, they should be able to understand the 'convention of the representation' and to construct a representation of any appropriate type for a given purpose [9]. Thus, in genetics education, lack of a clear convention of symbols for alleles may further confuse the learner.

Considering the reported difficulties experienced by students in understanding what alleles actually are $[18,20,28]$, and the fact that there is no conventional symbol system representing alleles in genetics education, it is reasonable to suggest that inconsistent use of allele symbols may affect 
students' ability to understand and use them. In this paper, we sought to better understand the existing symbol systems used in genetics textbooks and high-school students' conceptions of them.

Since textbooks provide a structure for classroom activities in science [29], we chose to focus, in the first stage, on mapping the symbol systems that are used in genetics textbooks and understanding the reasons for moving from one symbol system to another in each given book. In the second stage, we identified the meanings attributed by students to the differences in symbol systems used in genetics. Accordingly, our research questions were:

1. What are the symbol systems used in genetics textbooks and the justifications provided for their use?

2. How do students justify the use of different symbol systems when solving genetics problems?

\section{Materials and Methods}

\subsection{Mapping Genetics Textbooks}

We sought to understand which and how many symbol systems for alleles exist in genetics textbooks, and how the textbooks justify the shift from one symbol system to another in a given book. To gain a broad perspective of the existing symbol systems, we asked several colleagues to assist us in accessing textbooks that are widely used in their country for teaching high-school genetics. Overall, we analyzed 8 textbooks from 3 different countries worldwide (Israel, Spain and USA). These books are named here: A1-3 (Israel), B1-4 (Spain), and C1 (USA).

We first mapped all the symbol systems that occurred in each textbook. Then we searched for possible explanations for the choice of symbol systems and for shifting from one symbol system to another. Since the results did not yield any explicit explanation, but hinted at a contextual reason for the shift (see Section 3.1 Symbol Systems in Genetics Textbooks), we mapped the context in which each symbol system was used.

\subsection{Interviewing Students}

\subsubsection{Study Context}

While textbooks might or might not justify the use of several symbol systems, we aimed to understand how students justify their own use of different symbol systems. We interviewed eight 9th-grade students (age 14-15) learning in two different classes: two from Mr. A's class and six from Mrs. B's class. The students who were chosen to be interviewed were relatively verbal and their teachers testified to their academic performance being at an intermediate to high level.

Overall, in Mr. A's class, one high-cognitive-level student and one intermediate-level student were interviewed, and in Mrs. B's class, two high-cognitive-level and four intermediate-level students were interviewed. We named the high-cognitive-level students Abigail, Ben and Chen (Chen was from Mr. A's class), while the intermediate-level students were named Danielle, Enav, Felicity, Gali and Hila (Enav was from Mr. A's class). All names are pseudonyms.

Both classes were from the same urban high school and both studied genetics with one of the analyzed textbooks (textbook A3). Prior to studying about Mendel's principles of inheritance, students in both classes studied about meiosis and mitosis and about the central dogma of molecular biology.

\subsubsection{Data Sources}

During the semi-structured interviews, students were presented with a genetic phenomenon: two alleles for a certain gene affect the development of fruit fly eyes and leg muscles. In the case of leg muscle development, the two alleles demonstrated dominant/recessive relationships and the phenotypes were either normal muscles or abnormal muscles. However, in the case of eye development, the relationship between the same two alleles was incomplete dominance and the phenotypes ranged from normal eyes to small defective eyes to absence of eyes. These phenomena were chosen to explore 
the use of two different symbol systems for the same gene but in different tissues (eye or muscle). While there is no conventional or correct system for these phenomena, it allowed a discourse on which symbol system should be used and why. We also note that the Israeli curriculum for 9th-grade genetics does not include a distinction between co-dominance and incomplete dominance phenomena. As a result, students and teachers refer to both phenomena as co-dominance.

Along with the presentation of the phenomenon, students were given two different options to symbolize it: consistent use of the $\mathrm{A}^{1} \mathrm{~A}^{2}$ system (solution a) or alternation between the systems, using the Aa system to symbolize the inheritance paradigm of the leg muscles and the $\mathrm{A}^{1} \mathrm{~A}^{2}$ system to symbolize the inheritance paradigm of the eye (solution $b$ ). Following this presentation, we asked the students about their preference for one symbol system (uppercase/lowercase-D, d) usually used to represent dominant/recessive cases or the other (letter and number- $-\mathrm{D}^{1}, \mathrm{D}^{2}$ ) usually used to represent incomplete dominance. Students were also asked to give reasons for their preferences. Later, to further understand their inclination toward their system of choice, we asked the students about possible reasons for the differences that they observed between systems. We were specifically interested in answers to the following four questions:

(a) Does one of the solutions appear to be better or more correct to you? Which one and why?

(b) Why was the same letter (D) used to symbolize both phenomena?

(c) Do you prefer using one of the symbols over the other? Which one and why?

(d) If both symbols symbolize the same thing (same allele), why use different symbols?

It should be noted that asking the students which symbol system they preferred was deemed relevant only when students told us that they rely on their teacher's direction rather than a coherent rule when choosing a symbol system. In the case of students who methodically insisted that each system has its own use, asking for their preferred symbol system seemed irrelevant.

Interviews lasted from 20 to $28 \mathrm{~min}$ and were recorded (audio only).

\subsubsection{Data Analysis}

After transcribing the interviews, we used students' sentences as our unit of analysis. Data were reduced to include only those segments deemed relevant to our study. By relevant we mean answers to our protocol questions. These answers were similarly reduced to include only justifications for the use of a symbol or reasons for preferring a symbol. We were specifically interested in repeating patterns in the students' explanations that would enable us to understand how different students might comprehend the shift between symbol systems.

The interview transcripts were analyzed using an iterative process. Answers to interview questions a, c and d, were first divided into sentences. Coding categories were then developed to organize the data. Of interest to us were the differences between learners using genetic and non-genetic justifications when judging the different symbol systems. The transcripts were studied closely to determine whether certain patterns of thinking repeated and stood out, and to search for any regularities pertaining to these differences. Categories were further refined by working back and forth with the data and testing for our ability to operationalize it while adding more and more transcript segments.

Overall, 60 sentences were coded into the 5 different categories which emerged from our analysis. Of these 60 sentences, we were unable to code 3 sentences as these included justifications that we were unable to classify (such as "it is more convenient") or were too vague (such as metaphors which were not clarified during the interview). About 7 sentences were coded for each student. Inter-rater agreement was $93.33 \%$.

Question $b$ in the interview was used to confirm that students understood the biological context of our question and that they were able to refer to the microscopic entities being symbolized rather than the symbol itself. 


\section{Results}

\subsection{Symbol Systems in Genetics Textbooks}

To map the symbol systems used for the representation of alleles, we analyzed 8 books from 3 different countries. We found several different symbol systems that vary along and across books (Table 1). All of these symbol systems used Latin letters, some used only one letter, alternating between its lowercase and uppercase form (e.g., Aa), some used several letters (e.g., AB); some used numbers or added a tag to the letters (e.g., $\mathrm{AA}^{\prime}$ or $\mathrm{A}^{1} \mathrm{~A}^{2}$ ), and one system used letters combined with superscript letters (e.g., $\mathrm{I}^{\mathrm{A}} \mathrm{I}^{\mathrm{B}} \mathrm{i}$ ). Since most students study with only one textbook and are not usually exposed to others, we subsequently analyzed differences within each textbook.

On average, each textbook was found to have 2.3 symbol systems, meaning that at least 2 different systems were represented in every book. We attempted to find justifications for shifting from one symbol system to another in the textbooks themselves. However, no explicit explanation for these shifts was found in any of the studied textbooks. Although it was stated that it is customary to use a certain symbol for a specific allele, there was no discussion on the affordances and constraints of the symbol systems leading to this choice. For example, in textbook A1, two alleles for the gene encoding tyrosine transporter are presented, followed by this text:

"The allele for the production of a large amount of the tyrosine transporter protein will be represented as $B$ and the allele for the production of a small amount of the tyrosine transporter protein will be represented as $b$. Meaning, that for the gene for the tyrosine transporter protein there are two types of alleles: allele $B$ and allele $b . "$

In the same textbook, when the example of blood types is presented, the text reads:

"The allele for the production of enzyme A is customarily represented as $I^{A}$."

This type of wording was repeated in all the textbooks. Some textbooks did not use the word 'customary' but suggested that this is the way that the alleles should be represented, for example, in textbook $\mathrm{C} 1$ in the case of blood types:

"the $A B O$ group is determined by the alleles $A, B$ and $O$. A and $B$ alleles are both dominant over the O allele."

Similarly, in textbook B2:

"humans' blood type is co-defined by 3 different alleles: $A, B$ and $O$. A and B are co-dominant and rule over O."

This type of wording suggests that there is a customary manner to symbolize a specific allele. However, it does not provide an explanation for why the specific symbol is used and in fact, it does not even suggest that this symbol is part of a symbol system that should be used in this case.

The representation of a dominant allele by an uppercase letter and the recessive one by a lowercase letter is explicitly mentioned in some textbooks. For example, in textbook A1:

"It is customary to represent dominant alleles by upper case Latin letters and recessive alleles by lower case Latin letters."

In textbooks B1-B4 this is also explicitly written; textbook B4 adds this representation to explain the relationship "A > a". However, we could not find any other explanation for the remaining symbol systems in any of these textbooks, or the reason for shifting to another system. Such an explanation might be that in the case of co-dominance, both alleles are expressed in the phenotype, and it will thus be represented by an uppercase letter. In this case, to distinguish between the two uppercase A's, a number/tag, etc. must be added, or different letters used. 
Since the reasons for using a certain symbol system in a specific context are not explicitly specified, we mapped the context in which each symbol system was used (Table 1). From Table 1, it is clear that one of the main reasons for shifting from one symbol system to another is the allelic relationship. Cases that demonstrate dominant/recessive relationships (one allele is dominant over the other in terms of the appearance of the final trait) use a uniform symbol system in all textbooks (Aa) that differs from cases of co-dominance or incomplete dominance ( $\mathrm{AB}$ or $\mathrm{A}^{1} \mathrm{~A}^{2}$ or $\left.\mathrm{AA}^{\prime}\right)$.

The case of blood typing is a common example in genetics of two inheritance paradigms: (i) the co-dominant relationship paradigm, and (ii) the multiple-allele paradigm (more than two alleles for one gene). Some textbooks utilized this example to teach the symbol system used in that book for cases of multiple alleles (textbooks A1, B4, C1, B3). One textbook utilized blood typing to teach the symbol system used in that book for co-dominant relationships (textbook B2). Others did not refer to it as an example, but presented the specific case of blood typing (textbooks B1, A2).

These findings showed that there is no conventional symbol system used in textbooks and it is altered along textbooks according to specific contexts. In most cases, it seems that the contexts differed in the presentation of allelic relationships, but this was not true for all cases and those textbooks never clearly justified the shift to a different symbol system. This lack of an explicit explanation regarding the conventions leading to the use of a symbol system might be confusing to students. This is because the ability to construct meaning from a symbol depends on conventions regarding the content described by the symbol (Peirce, 1906; Schnotz, 2002; Schnotz \& Bannert, 2003). Thus, it was of interest to understand how students who studied with one of these textbooks dealt with the inconsistencies in the symbol systems, and how they justified their use of different symbol systems.

Table 1. Mapping of allele symbols used in several genetics textbooks.

\begin{tabular}{|c|c|c|}
\hline Textbook & Symbol System & Context \\
\hline \multirow{3}{*}{ A1 } & Uppercase/lowercase (A, a) & Dominant/recessive \\
\hline & One letter accompanied by another letter $\left(\mathrm{I}^{\mathrm{A}}, \mathrm{I}^{\mathrm{B}}, \mathrm{i}\right)$ & Blood types as an example of multiple alleles \\
\hline & Two distinct letters $(\mathrm{A}, \mathrm{S})$ & Symbols for hemoglobin (in relation to sickle cell anemia) \\
\hline \multirow{3}{*}{$\mathrm{A} 2$} & Uppercase/lowercase (A, a) & Dominant/recessive \\
\hline & One letter accompanied by a number $\left(\mathrm{A}^{1}, \mathrm{~A}^{2}\right)$ & Incomplete dominance \\
\hline & One letter accompanied by another letter $\left(\mathrm{I}^{\mathrm{A}}, \mathrm{I}^{\mathrm{B}}, \mathrm{i}\right)$ & Blood types \\
\hline \multirow{3}{*}{$\mathrm{A} 3$} & Uppercase/lowercase (A, a) & Dominant/recessive \\
\hline & One letter accompanied by a number $\left(\mathrm{A}^{1}, \mathrm{~A}^{2}\right)$ & Incomplete dominance \\
\hline & One letter accompanied by another letter $\left(\mathrm{I}^{\mathrm{A}}, \mathrm{I}^{\mathrm{B}}, \mathrm{i}\right)$ & Blood types as an example for multiple alleles \\
\hline \multirow{2}{*}{ B1 } & Uppercase/lowercase (A, a) & Dominant/recessive \\
\hline & Three distinct letters $(\mathrm{A} / \mathrm{B} / \mathrm{O})$ & Blood type \\
\hline \multirow{2}{*}{ B2 } & Uppercase/lowercase (A, a) & Dominant/recessive \\
\hline & Three distinct letters $(\mathrm{A} / \mathrm{B} / \mathrm{O})$ & Blood type as an example of co-dominance \\
\hline \multirow{2}{*}{ B3 } & Uppercase/lowercase (A, a) & Dominant/recessive \\
\hline & One letter with/without a tag (A/A') & Co-dominance \\
\hline \multirow{2}{*}{ B4 } & Uppercase/lowercase (A, a) & Dominant/recessive \\
\hline & Three distinct letters $(\mathrm{A} / \mathrm{B} / \mathrm{O})$ & Blood type as an example of multiple alleles \\
\hline \multirow{4}{*}{$\mathrm{C} 1$} & Uppercase/lowercase (A, a) & Dominant/recessive \\
\hline & Three distinct letters $(\mathrm{A} / \mathrm{B} / \mathrm{O})$ & Blood type as an example of multiple alleles \\
\hline & One letter with/without a tag $\left(\mathrm{A} / \mathrm{A}^{\prime}\right)$ & Incomplete dominance \\
\hline & $\mathrm{X}$ for a chromosome and another letter for the allele $\left(\mathrm{X}^{\mathrm{A}} / \mathrm{X}\right)$ & Sex linkage \\
\hline
\end{tabular}

\subsection{Students' Justifications for the Use of Different Symbol Systems}

To understand how students justify the use of several symbol systems when learning about alleles, we presented them with an irregular phenomenon along with two different solutions symbolizing this phenomenon. Following this presentation, we asked them which solution they preferred and what differences they observed between the systems.

An answer that was common to all students was recorded when students were asked to explain why the letter D is used consistently in both Punnet squares. All students stated that it is the same gene and hence the same letter. Overall, 12 similar arguments pertaining to the use of the letter D were provided by the 8 interviewed students. As an example, here are Ben and Gali's answers: 
Ben: "It would just complicate things if we used more than one letter for the same gene."

Gali: "No, [I would use] the same letter, because they told me it's the same gene that affects both traits, so I would mark it, like, with the same letter."

In addition to the students' agreement on the consistent use of the letter D, we also recognized that all students preferred solution $b$. Based only on this choice, we could not determine whether the students preferred the use of two distinct symbol systems or refrained from using only the $\mathrm{A}^{1} \mathrm{~A}^{2}$ system (students were not given the option to choose a solution with Aa only). Therefore, we sought to understand why the students made this choice. Our method, of asking the students to provide an argument and justify their choices, allowed us to identify two types of students, who differed by the justifications for their choice and by the approach that they used to compare the two symbol systems. The first type included students who relied on arguments that were deeply embedded in the biological context, while the second type included students who did not rely on genetic arguments.

\subsubsection{Type 1: Students Relying on Arguments Deeply Embedded in the Genetic Context}

The first type of student ( 3 out of 8 ) used justifications that were deeply embedded in the genetic context of the problem, specifically the allelic relationship. For example, after observing the two possible solutions, when asked to choose a solution and justify his choice, Ben said:

"Because in the first solution, if the two alleles are co-dominant then $D^{1}$ and $D^{2}$ together will create something new and different, between a functional and non-functional leg, and it doesn't say that it's possible that something like this will happen. So, it's much more logical that they're just dominant and recessive."

Ben's argument clearly shows that he is looking for biological clues when trying to determine which set is more appropriate for this problem. Understanding that the "something new and different" he observed was a third phenotype, we see in his argument an attempt to justify his choice on the number of phenotypes embodied in the leg phenomenon. Therefore, it would seem that Ben relies on his knowledge about co-dominance and dominance/recessiveness to form his argument.

A similar argument can be observed in Abigail's and Chen's answers to the same question. Both students chose solution $\mathrm{b}$ as more suitable and provided arguments based on the allelic relationship:

Chen: " ... and I think solution two is more logical because right here you can see that the dominant is a functional leg, now that means that these two [Punnet squares of solution b] are correct, that the dominant affects the recessive."

Abigail: "What I mentioned, in the beginning, that here it refers to this in the heredity of the recessive or dominant gene, and then it's more suitable to write it using a lowercase $d$ and an uppercase D. Here it's co-dominance, so $D^{1}$ and $D^{2}$ is more suitable."

Just like Ben, to make sense of, and justify their choice, Chen and Abigail referred to the biological nature of the alleles. Interestingly, enough, Abigail quickly added to her argument that:

"Heredity of dominant and recessive, so, according to how they taught us in the classroom, then you write it with a capital letter and a lowercase letter, although in reality, that [solution a] comes out right too."

Although Abigail mentions her teacher as a motive for using a symbolic convention, she can explain how the symbol represents the biological entities in the problem. Furthermore, she mentions the possibility of using a different symbol system. This remark becomes even more important after she mentions that both phenomena are caused by the same gene, and is asked why one should use a different convention for the same object: 
"Because I think that as long as it's the same letter and we know it's the same gene, um, but it's more accurate when it's written like that. It explains to us the modes of inheritance by which it is transferred."

In a similar way, when asked about the use of two different conventions for symbolizing the same object, Ben stated:

"Because here they work as dominant-recessive and they're not co-dominant. They're not creating anything new. So the same alleles will be marked differently and they will create two different traits. And in one trait they will be marked as co-dominant and in the other, they will be marked dominant-recessive."

Much like his peers, Ben insisted that the main reason for choosing a symbolic convention and using it is the co-dominant or dominant-recessive nature of the allele. He pointed out that the choice in itself gives information about the nature of these alleles, although that nature changed across the examples that he was given. Ben was so convinced in his argument that when asked whether this could be a source of confusion between different scientists he answered:

"Yes, it could, but I just don't think it's efficient to represent it like this because they're simply not co-dominant."

In a similar way, Chen points out:

"I think that strengthens the argument [to use one convention only] but it just doesn't make sense that they are dominant."

Given these data, we observed that throughout the interview, Abigail, Ben and Chen kept referring to biological entities, qualities and processes to justify the use of each symbolic convention. It seems that they have absorbed the rule implied by their textbook of using different symbol systems for different allelic relationships. Interestingly, these justifications also included a vast number and variety of biological terms, such as dominance of alleles, co-dominance, genes, heterozygosity, etc. When asked whether the two systems should be unified into a single one, these students justified their choice and articulated their thoughts in the same manner.

It should be emphasized that students' reasoning in this group was almost completely consistent with its answers. Overall, 13 of the 14 justifications provided by type 1 students were of the allelic relationship type. In only one instance, a student in this group (Chen) mentioned that overall, the use of symbols is just to avoid confusion.

\subsubsection{Type 2: Students Relying on Non-Genetic Arguments}

While all the type 1 students were able to tie their arguments to the relationships between the alleles in the phenomenon displayed to them, 5 out of the 8 interviewed students provided justifications of a different nature.

Take, for example, Gali's preference for the Aa system and especially her reluctance to use the $\mathrm{A}^{1} \mathrm{~A}^{2}$ system:

"It's easier for me to label it this way (Aa), unless the direction was to label it with this $\left[A^{1} A^{2}\right]$, um,

I forgot how you call that capital letter with the number."

We could not determine, from this statement, why Gali prefers the Aa system; however, it is clear in this example that Gali is unable to name the context in which the $\mathrm{A}^{1} \mathrm{~A}^{2}$ system is used and we can only assume that she is referring to the context of co-dominance. While this could be just a matter of recalling the right name, we noticed that Gali is talking about a direction, meaning an external authority directing the choice of symbol system. We understand, from her choice of words, that one symbol system is convenient whereas the other is to be used when called upon by a directive. With an attempt to clarify why the two systems coexist, Gali was later asked if she ever used the $\mathrm{A}^{1} \mathrm{~A}^{2}$ system and if so, when? To this she replied: 
"Yes, we had a test. Not on the test ... actually, she [the teacher] didn't say and still I wrote ... like, I don't really remember why I wrote it. It was like, in the question ... I don't really remember ... because the heading of the test had this word that I don't remember."

It would seem that Gali's justification for using the $\mathrm{A}^{1} \mathrm{~A}^{2}$ system is the way in which the question is presented. When the question detailed the use of the $\mathrm{A}^{1} \mathrm{~A}^{2}$ system, probably using the word co-codominance, Gali used it. It is interesting to note that Gali repeatedly links the $\mathrm{A}^{1} \mathrm{~A}^{2}$ system with the word that she does not remember, but does not give any meaning to that word.

Much like Gali, Enav's justification is based on an external authority dictating the use of the system. When asked whether she ever solved a problem using the $\mathrm{A}^{1} \mathrm{~A}^{2}$ system, she answers:

"Yes, these things, uh, with 1 and 2? So, in class I had to do a project on genetic illnesses and we did this comparison and that's how it showed up on the internet."

While Enav mentions the Internet and not her teacher in her argument, we noticed that both arguments refer to an external source of authority. In both Gali's and Enav's arguments, the scientific context is missing, resulting in a justification-based simply on authority and nothing else. This evidence is even more meaningful when considering the scientific context that is evident in Abigail's, Ben's and Chen's arguments.

A similar justification can be seen in Felicity's argument when she is asked why the solution b includes the use of two symbol systems:

"You do this when you talk about, um, there's like no separation in this but somehow when she [the teacher] writes it on the board then sometimes she does this and sometimes that. So there's some kind of separation but in reality, it should say the same thing."

Once again, and similar to Abigail's argument, Felicity talks about the nature of symbols as a denotation of an object: both symbol systems say "the same thing". However, while Abigail mentions a possible source for the separation (allelic relationship), Felicity seems to be unable to state this source and is thus left with "sometimes she does this and sometimes that".

Of the 5 type 2 students, Hila was the only one who did not mention a clear external authority for the use of the $\mathrm{A}^{1} \mathrm{~A}^{2}$ system. She did, however, state that:

"The ratio between the big eye and the little eye is different than that between the normal and abnormal leg."

However, she was unable to explain what she means by 'ratio'. Instead, when the interviewer probed further and suggested eliminating the use of the $\mathrm{A}^{1} \mathrm{~A}^{2}$ system altogether, she exclaims:

"That probably won't be accurate, because there must be a reason for putting numbers in addition to the two lowercase d's."

As both solutions presented to the students included the $\mathrm{A}^{1} \mathrm{~A}^{2}$ system, we presume that this gave Hila the impression that the $\mathrm{A}^{1} \mathrm{~A}^{2}$ system must be efficient in some way. In a way, she refers to the question presented by the interviewer as a source of external authority. This was later confirmed as she claimed that she does prefer using just the Aa system, but:

"It would be more convenient, but there must be a reason they didn't do that. I want to believe that there's a reason."

Once again, Hila is accepting the $\mathrm{A}^{1} \mathrm{~A}^{2}$ system as a valid, efficient symbol system, but she is unable to explain when it should be used.

While the external authority justifications were evident in all the type 2 students' statements, we recognized other justifications as well. These were not of the external kind, but actually referred to the students' personal preferences. One such preference can be seen in Felicity's claim that using the Aa system is: 
"clearer to the eye, because here $\left[D^{1} D^{2}\right]$ you see two D's and you need to look at the number, and here [Dd] you see the difference."

Felicity, in this case, is referring to the graphic nature of the symbols, basing her preference for one of the systems on the fact that it holds less symbols. Furthermore, when she is asked why the Aa system is clearer, she claims that:

"I think it makes it easier for me because it's still as if there's a difference between them but it's still as if they are the same with a difference between them."

Similarly, Danielle talks about her preference toward the Aa system and later elaborates:

"Truthfully, $D^{1}$ and $D^{2}$ confuses me, like you saw. I prefer using capital D and lowercase d...Less numbers."

Gali, similar to Felicity, claims that the Aa system is easier to use because:

"It really shows me the difference."

Furthermore, later, Gali claims that completely different letters for each allele (such as A and B) would have been even better. On a very similar note, toward the end of the interview, and although previously she showed a preference for the Aa system, Hila posits that the Aa system might actually be confusing and that solution a, containing only the $\mathrm{A}^{1} \mathrm{~A}^{2}$ system, is better:

"... for the simple reason that I won't have those misguided associations about dominant and non-dominant. That's how I got used to thinking."

In summary, all type 2 students, apart from Enav, referred to the graphical nature of the symbol and based their preference upon it. However, this was not the only reason students gave as a basis for their bias. While Danielle claimed that she prefers "less numbers", she also states that:

"It's not that the numbers are confusing, it's just that from the beginning, in class, we learned that the capital $D$ is dominant and the lowercase dis recessive. It's easier for me to see that it's capital and lowercase."

Danielle seems to be listing two reasons for choosing the Aa system. The first is the graphical nature of the symbol; however, she does have reservations and thus adds another reason for disliking the $\mathrm{A}^{1} \mathrm{~A}^{2}$ system - her previous exposure to the Aa system. A similar argument can be seen in Enav's and Hila's interviews:

Enav: "The letters, I'm more used to working with them. In class we use the capital, lowercase letters. Not that it's critical."

Hila: "I think I would choose solution B (with the Aa system) because it's much more familiar to me."

While most type 2 students desired a unification of the systems, with a strong preference for one of the systems, Felicity actually preferred the use of different symbol systems. This preference was based on a reason we could only identify in Felicity's interview:

"We're talking about eyes here and legs here, so it was easier when it's different symbols."

According to Felicity, the use of two symbol systems is easier for her because it helps her keep the two tissues separate. This motive, of keeping a symbol system for the eyes and a symbol system for the legs, becomes even clearer when she is asked whether different letters would have made it easier for her and she claims that it would have:

"It's much more logical for me when there's a separation between the, um, that if you talk about one thing it has a letter and if you talk about something else it has a different letter." 
While Felicity might be aware of some Mendelian difference between the inheritance paradigms of the eyes and leg muscles, she does not state it. Furthermore, while the $\mathrm{A}^{1} \mathrm{~A}^{2}$ system might be convenient for symbolizing co-dominance, Felicity is clearly interested in simply keeping the 'things' separate. Thus, her criterion for this separation is the organ where the phenomenon is occurring, and not the inheritance pattern itself.

Set apart from the described narrative was the case of Hila. While most students displayed a consistent approach, i.e., basing or not basing their arguments on the inheritance paradigm, we were fascinated to witness one atypical type 2 student who shifted from one course of reasoning to another. While Hila preferred use of the Aa system at the beginning of the interview and could only justify use of the $\mathrm{A}^{1} \mathrm{~A}^{2}$ system by referring to an external authority, during the interview, she was asked to point out the dominant allele in the eyes. Unable to do so (as the alleles exhibit incomplete dominance), she began a self-exploration of the displayed symbols. At the end of it, she was asked whether this justifies the use of the $\mathrm{A}^{1} \mathrm{~A}^{2}$ system, to which she answered:

"So maybe it can explain this choice, because they have the same strength, so it's the same capital letter, but what distinguishes them is the 1 and 2."

Toward the middle of the interview, Hila began to recognize an abnormality: the inheritance paradigm of co-dominance. As she was uncomfortable symbolizing this paradigm using the Aa system, she began to justify the use of the $\mathrm{A}^{1} \mathrm{~A}^{2}$ system in a different way. This part of the interview allowed us to code 4 of the justifications that she provided as based on allelic relationships. Furthermore, she did something none of the other 7 students did, and that is to talk about the meaning of the symbol in a way that can be viewed as meta-visualization.

In conclusion, we identified a group of students whose explanations failed to link the two inheritance paradigms and the two symbol systems. Those students followed conventions set by an external authority (11 justifications of this type were recorded) when required to choose one of the systems. Furthermore, when asked to give their own reasons for preferring any or both symbol systems, they relied on the graphical nature of the symbol (6 justifications of this type were recorded). The same students also expressed either a personal inclination toward unification of the systems, to avoid confusion (8 justifications of this type were recorded), or separation of the systems, to emphasize the differences between the two cases (i.e., eyes and legs, only 2 justifications of this type were recorded). As opposed to the overall consistency in the group's non-genetic arguments, 4 allelic relationship justifications were presented by Hila. All 4 appeared after the interviewer asked her to point out the dominant allele in the eye phenomenon.

\section{Discussion}

In this study, we aimed to learn more about the symbol systems used to represent alleles in genetics textbooks, and to understand how students justify their use. We found several symbol systems for alleles coexisting along and across genetics textbooks. We also found that the transition from one system to another is not clearly explained in those books. After mapping the symbol systems and the context in which each system was presented, we found that the symbol system changes when the presented phenomenon exemplifies different allelic relationships or when there are more than two alleles for one gene.

Finding the contextual reasons for changing the symbols allowed us to understand how the limitations of a particular symbol system require shifting to another system: in all the textbooks, the first symbol system presented was of uppercase/lowercase letters to symbolize alleles in a dominant/recessive relationship. The dominant allele was always marked by the uppercase letter and the recessive one by the lowercase letter, indicating that this system is one convention across all textbooks. Using this system, it is not possible to symbolize more than two alleles because there are only two possibilities, uppercase or lowercase. Similarly, it is not possible to use this system to symbolize two co-dominant alleles of the same gene since both would be marked by the same symbol, 
making the two symbols indistinguishable. Considering that this is the first system presented in all textbooks, it is clear why another system is needed to symbolize cases of co-dominance/partial dominance or multiple alleles.

This 'birds'-eye view' of the symbol systems may not be accessible to novice students without explicit explanations. Understanding the meaning of a symbol is not only knowing which object it represents, but also acknowledging its limitations in representing the object $[3,9,30]$. To enable communication using symbols, the meaning that is embedded in a symbol by its creator must be understood by all those who perceive it [1].

As already noted, the field of genetics is challenging for students, who exhibit difficulties in understanding the concepts of genes and their different versions, termed alleles $[11,19,20,23]$. Consequently, they use the symbols of alleles as an algorithm to solve problems without necessarily knowing the underlying concepts that teachers expect them to know after instruction, and they do this while conveying incorrect conceptual knowledge [21,22]. Allele symbols, on the other hand, are a main means of communication for displaying and explaining processes and models of allelic relationships. As in the past, lack of convention regarding visual representations gave rise to doubts as to their effect on the understanding of the object being symbolized [31], we could only suspect that adding confusion to the already apparent difficulties for novices might lead to complications in communication using these allelic symbols.

Indeed, this was apparent in our examination of the justifications provided by students for the existence and use of two different symbol systems. Findings indicated that some students (which we refer to as type 1 students) can link the change in the inheritance paradigm to the change in the symbol system used. However, several students (which we refer to as type 2 students) could not do so. Unable to explicitly name this link, these students relied on an external authority (such as the teacher or the Internet) that arbitrarily determined which symbol system should be used in each case. Without understanding the rationale behind the use of multiple representations, the students justified the existence of any representation with non-genetic justifications. In almost none of the cases did this lead them to the justification of two complementary representations.

It might be argued that some of the interviewed students interpreted our questions differently. Following the logic of this argument, higher-level students were able to understand our intention to talk about the inheritance paradigm, whereas lower-level students thought that we were talking about their personal disposition or the identity of the entity responsible for symbolic conventions (i.e., the teacher or the scientific community). However, even students who insisted on ignoring the allelic relationship as a guideline for choosing the symbol system were prone to point out the gene itself (i.e., the object) as the reason for the constant use of the letter ' $d$ ' (i.e., the symbol). Furthermore, as the pattern of answers surfaced repeatedly in each group when faced with different questions, and as all students displayed this pattern almost exclusively, we cannot ignore the fact that some of the interviewed students relied on the link between the inheritance paradigm and the symbols to justify the use of the symbols and some of them were unable to do so.

Overall, our results suggest that the absence of a clear conventional symbol system and the lack of explanations concerning the reason for shifting from one symbol system to another might hinder the understanding of the connection between the symbol and the object that it symbolizes. Learners might give an incorrect meaning to the switch between one symbol system and another or even ignore the meaning altogether, missing an important concept (such as the inheritance paradigm) embedded in the rationale behind the switch.

These results support the "deep-level" and "surface-level" reasoning described in previous studies with respect to the use of representations by novice students [6,32]. When comparing the way in which experts and novices implement conceptual knowledge, it has been found that the latter use surface features of the visual representation when assessing them, as opposed to the former who are able to use deeper conceptual knowledge when given a sorting task. For example, when novices were asked to sort visual representations from different media (videos, graphs, images, etc.) they tended to group 
them either by media or by surface features of the phenomenon, such as "molecules moving around". Experts, on the other hand, tended to group more cross-media examples together and used deep conceptual knowledge such as "precipitation" or "equilibrium" to sort visual representations [6,32]. We suggest that students who linked the symbol system to the inheritance paradigm and valued the use of both symbol systems were able to display deep-level reasoning. On the other hand, our findings suggest that students who displayed a preference for one of the symbol systems based on graphical features, such as the addition of numerals, were unable to use deep-level reasoning and resorted to the evaluation of surface features of the symbol system.

While students who relied on surface features of the symbol system displayed a preference for one of the systems, we also identified one type 2 student who did justify the switch between the two symbol systems, yet was unable to link this switch to the inheritance paradigm. This student justified the use of two systems based on the existence of two different tissues in the displayed phenomenon. Results from a previous study have demonstrated that novice students tend to understand and focus more on observable structures than on more complex features, such as behaviors and functions [33]. The authors of that study concluded that experts, on the other hand, view the behavioral and functional understanding of the system as a deep principle, which facilitates the organization of their knowledge of the system. Unable to link the $\mathrm{A}^{1} \mathrm{~A}^{2}$ system to co-dominance, the interviewed student linked the use of a different symbol system to a surface feature that we did not expect to be significant: tissue type. As such, we find that student's justification and analysis to be consistent with these previous findings. We suggest that while the student was able to judge the alleles by a simple property (location), she was unable to properly analyze and organize the information according to the allele's behavior. Our results suggest that just like structure, some entities' properties are easier to understand and therefore easier to link to features of the visual representation for the novice learner.

We view our students' justifications as evidence for the use of surface features, of either the symbol or the object represented by it, for the evaluation and processing of visual representations. We suggest that as type 2 students lacked the tools to use deep-level reasoning, they resorted to any surface feature available to them. Consequently, while these students had no apparent trouble identifying crucial features of the visual representation itself (letters, numbers, etc.), their focus on surface features constrained their ability to link the representation's features to meaningful biological concepts.

Another possible interpretation to our data can be suggested. As the evidence clearly shows a correlation between the level of the students (as reported by the teacher) and the type of arguments they provided, it could be argued that students with lower academic performance who lacked content knowledge turned to surface explanations to meet the expectations of the interviewer. It is important to point out that while we did record several instances in which type 2 students could not recall key terms (such as co-dominance) and made improper use of others during the interview, they did make proper use of several terms which are considered a source of confusion in genetics education. For example, we could recognize in all students' discourse a clear separation between genes and alleles, a known hurdle in the biology classroom for both students and teachers $[25,26,34]$. Furthermore, we do acknowledge that we have no ability, in this study, to determine whether the use of several symbol systems in the classroom confused students and prevented them from using deep-level reasoning. However, it was quite apparent to us that for some of the students, the introduction of several symbol systems to the classroom was not a strong enough instigator to promote deep-level reasoning concerning the difference between the two inheritance paradigms they represent.

While using a small sample of 8 students allowed us to deeply probe and focus on meaningful justifications in students' reasoning, we acknowledge this small sample as a limitation of our study, as this method prohibits us from claiming that our results can be generalizable. Thus, we cannot claim that all classes display the same type of students as we have observed, and we do not claim any knowledge as to the distribution of arguments within the classroom we observed or any other classroom for that matter. We do claim, however, that our results provide some insight into the 
complexity of introducing multiple visual representations into the classroom. This study supports the suggestion that further attention to this issue is required.

While studies on the use of multiple representations in the classroom exist [12,15,35-37], they all focus on the pros and cons of multiple visual representations. However, whereas all these aim to guide the teacher in choosing representations for his or her students, there seems to be a question that garners less attention: "Does the student understand why we use multiple representations in the classroom?"

We wish to emphasize that students who preferred the Aa system were showing a preference for the very first symbol system they had encountered in their introduction to Mendelian genetics in the classroom. As we elaborated earlier, considering that in all textbooks, this is the first symbol system presented, it is clear why another symbol system is needed to symbolize cases of co-dominance/partial dominance or multiple alleles. While these are just causes to switch to a different symbol system, none of them are explicitly stated in the students' textbooks. It was quite apparent to us that some of the students were unable to understand the reason for switching to a different visual representation. As novices tend to focus on the surface features of the representation, some students viewed the added representations as redundant, differing from the previous ones only due to superficial characteristics. While it could be postulated that the introduction of a new visual representation will trigger an assumption in the learner of the introduction of a new phenomenon or concept, this assumption was not triggered in some of the students that we interviewed.

A similar phenomenon was observed by Gericke, Hagberg, and Jorde [38] as they introduced students with different texts containing incommensurable models of gene function, both of them present in the genetics classroom. From this study's data, it would seem that students fail to notice any contradictions between the texts or any of the different epistemological features presented by them. Similarly, some of them find it difficult to justify the co-existence of these two models. One of the conclusions of the authors was that this difficulty, combined with the absence of an explicit embedded explanation regarding the variation in models, might be the source of hybrid models, created by the students. These hybrid models might lead to student difficulties in learning.

As the effect of a missing explanation regarding variation in models or symbols becomes clearer and as the knowledge pertaining to the reason for using each of the different symbol systems seemed flawed while interviewing some of our students, we first questioned the need for two symbol systems in genetics teaching. Although the Aa system has its constraints, the $\mathrm{A}^{1} \mathrm{~A}^{2}$ system can be used as a ubiquitous default visual representation for any of the inheritance paradigms. While we do acknowledge that some scientific communities use uppercase letters to denote dominant alleles [39], if truly needed, teachers can introduce this information to the learners later in the process, after they have established a better understanding of the term allele and its symbols.

Whereas we view the use of one symbol system as convenient, the use of multiple symbol systems is currently common practice, as seen through the analysis of the genetics textbooks. As a conclusion from our study, we recommend that this practice be used with care and thought. While the textbooks that we reviewed bore no explanation for the reason to switch between symbol systems, we wish to point out the merits of creating such a discussion on the reason for this switch and mainly the constraints of the Aa system. This discussion might allow students to understand the relationship between the two systems, strengthen the connection between the symbols and the models that they symbolize, and lead to a better understanding of the relevant concepts. A previous work on "models of modeling" demonstrated this process, as students who were tasked with the analysis of the relations between representations acquired a more fluent visualization capability [3]. Similarly, we view one of our students' interviews as evidence of such a process, as a dialogue with her during the interview was followed by a change in the type of justifications that she provided (Hila, see Section 3.2.2).

In conclusion, we show that textbooks in genetics education use different symbol systems to represent alleles. Each system that we surveyed is linked, in the textbook, to a different inheritance paradigm or to a unique phenomenon. However, this switch between symbol systems is not explained in the reviewed textbooks. While we, as researchers, were able to speculate about the reason for the 
switch and while some students that we interviewed were able to link each symbol system to the correct inheritance paradigm, some of the interviewed students were unable to do so. These latter students justified the application of two different systems using surface reasoning and related them to surface features of the phenomenon.

While educators might use different visual representations to elaborate and represent different features of an object, process or system, the use of multiple visual representations should be practiced with care. We propose that any addition of a new visual representation should be accompanied by a discussion, both in the classroom and in the textbook, about the flaws of the previous representation and the need to introduce the new one. Without such a dialogue, which includes the affordances and constraints of the representation, students are left with routine tasks, stripped of context and devoid of deep conceptual understanding, especially when a different, known and usable visual representation has already been presented to them. After all, for the novice student, it is never as simple as that.

Author Contributions: Conceptualization, M.H.-I.; Data collection and analysis, G.A.L.-A. and M.H.-I.; Writing, Review \& Editing, G.A.L.-A., M.H.-I., A.Y.

Funding: This work was supported by a postdoctoral fellowship from the Dean of Education at the Weizmann Institute of Science and the Weizmann-Abroad Postdoctoral Grant for Advancing Women in Science.

Acknowledgments: We would like to thank Ravit G. Duncan, Veronica Cavera and Lucía Vázquez Ben for enabling the access to some of the analyzed textbooks. We thank the members of our group for fruitful discussions.

Conflicts of Interest: The authors declare no conflict of interest.

\section{References}

1. Gilbert, J.K.; Justi, R. The Contribution of Visualisation to Modelling-Based Teaching. In Modelling-Based Teaching in Science Education; Springer International Publishing: Cham, Switzerland, 2016; pp. 121-148.

2. Duval, R. A Cognitive Analysis of Problems of Comprehension in a Learning of Mathematics. Educ. Stud. Math. 2006, 61, 103-131. [CrossRef]

3. Justi, R.; Gilbert, J.K.; Ferreira, P.F.M. The Application of a 'Model of Modelling' to Illustrate the Importance of Metavisualisation in Respect of the Three Types of Representation. In Multiple Representations in Chemical Education; Models and Modeling in Science Education; Gilbert, J.K., Treagust, D., Eds.; Springer: Dordrecht, The Netherlands, 2009; Volume 4, pp. 285-307.

4. Kozma, R.; Russell, J. Students Becoming Chemists: Developing Representational Competence. In Visualization in Science Education; Springer: Dordrecht, The Netherlands, 2005; pp. 121-145.

5. Keig, P.F.; Rubba, P.A. Translation of Representations of the Structure of Matter and Its Relationship to Reasoning, Gender, Spatial Reasoning, and Specific Prior Knowledge. J. Res. Sci. Teach. 1993, 30, 883-903. [CrossRef]

6. Kozma, R.; Russell, J. Multimedia and Understanding: Expert and Novice Responses to Different Representations of Chemical Phenomena. J. Res. Sci. Teach. 1997, 34, 949-968. [CrossRef]

7. Van Mil, M.H.W.; Boerwinkel, D.J.; Waarlo, A.J. Modelling Molecular Mechanisms: A Framework of Scientific Reasoning to Construct Molecular-Level Explanations for Cellular Behaviour. Sci. Educ. 2013, 22, 93-118. [CrossRef]

8. Schönborn, K.J.; Anderson, T.R.; Grayson, D.J. Student Difficulties with the Interpretation of a Textbook Diagram of Immunoglobulin G (IgG). Biochem. Mol. Biol. Educ. 2002, 30, 93-97. [CrossRef]

9. Gilbert, J.K. Visualization: A Metacognitive Skill in Science and Science Education. In Visualization in Science Education; Gilbert, J.K., Ed.; Springer: Dordrecht, The Netherlands, 2005; pp. 9-27.

10. Johnstone, A.H. Why Is Science Difficult to Learn? Things Are Seldom What They Seem. J. Comput. Assist. Learn. 1991, 7, 75-83. [CrossRef]

11. Marbach-Ad, G.; Stavy, R. Students' Cellular and Molecular Explanations of Genetic Phenomena. J. Biol. Educ. 2000, 34, 200-205. [CrossRef]

12. Ainsworth, S. The Educational Value of Multiple-Representations When Learning Complex Scientific Concepts. In Visualization: Theory and Practice in Science Education; Gilbert, J.K., Reiner, M., Nakhleh, M., Eds.; Springer: Dordrecht, The Netherlands, 2008; pp. 191-208.

13. Peirce, C.S. Prolegomena to an Apology for Pragmaticism. Monist 1906, 16, 492-546. [CrossRef] 
14. Schnotz, W. Towards an Integrated View of Learning from Text and Visual Displays. Educ. Psychol. Rev. 2002, 14, 101-120. [CrossRef]

15. Schnotz, W.; Bannert, M. Construction and Interference in Learning from Multiple Representation. Learn. Instr. 2003, 13, 141-156. [CrossRef]

16. Markovits, Z.; Sowder, J.T. Students' Understanding of the Relationship between Fractions and Decimals. Focus Learn. Probl. Math. 1991, 13, 3-11.

17. Vamvakoussi, X.; Vosniadou, S. How Many Decimals Are There between Two Fractions? Aspects of Secondary School Students' Understanding of Rational Numbers and Their Notation. Cognit. Instr. 2010, 28, 181-209. [CrossRef]

18. Marbach-Ad, G. Attempting to Break the Code in Student Comprehension of Genetic Concepts. J. Biol. Educ. 2001, 35, 183-189. [CrossRef]

19. Duncan, R.G.; Reiser, B.J. Reasoning across Ontologically Distinct Levels: Students' Understandings of Molecular Genetics. J. Res. Sci. Teach. 2007, 44, 938-959. [CrossRef]

20. Haskel-Ittah, M.; Yarden, A. Toward Bridging the Mechanistic Gap Between Genes and Traits by Emphasizing the Role of Proteins in a Computational Environment. Sci. Educ. 2017, 26, 1143-1160. [CrossRef]

21. Stewart, J.; Van Kirk, J. Understanding and Problem-Solving in Classical Genetics. Int. J. Sci. Educ. 1990, 12, 575-588. [CrossRef]

22. Wynne, C.F.; Stewart, J.; Passmore, C. High School Students' Use of Meiosis When Solving Genetics Problems. Int. J. Sci. Educ. 2001, 23, 501-515. [CrossRef]

23. Gericke, N.M.; Hagberg, M. Conceptual Incoherence as a Result of the Use of Multiple Historical Models in School Textbooks. Res. Sci. Educ. 2010, 40, 605-623. [CrossRef]

24. Wood-Robinson, C. Young People's Ideas about Inheritance and Evolution. Stud. Sci. Educ. 1994, 24, $29-47$. [CrossRef]

25. Pashley, M. A-Level Students: Their Problems with Gene and Allele. J. Biol. Educ. 1994, 28, 120-126. [CrossRef]

26. Lewis, J.; Leach, J.; Wood-Robinson, C. All in the Genes?-Young People's Understanding of the Nature of Genes. J. Biol. Educ. 2000, 34, 74-79. [CrossRef]

27. Wood-Robinson, C.; Lewis, J.; Leach, J. Young People's Understanding of the Nature of Genetic Information in the Cells of an Organism. J. Biol. Educ. 2000, 35, 29-36. [CrossRef]

28. Duncan, R.G.; Castro-Faix, M.; Choi, J. Informing A Learning Progression in Genetics: Which Should Be Taught First, Mendelian Inheritance or the Central Dogma of Molecular Biology. Int. J. Sci. Math. Educ. 2016, 14, 445-472. [CrossRef]

29. Digisi, L.L.; Willett, J.B. What High School Biology Teachers Say about Their Textbook Use: A Descriptive Study. J. Res. Sci. Teach. 1995, 32, 123-142. [CrossRef]

30. Justi, R.; Gilbert, J.K. Modelling, Teachers' Views on the Nature of Modelling, and Implications for the Education of Modellers. Int. J. Sci. Educ. 2002, 24, 369-387. [CrossRef]

31. Schönborn, K.J.; Anderson, T.R. A Model of Factors Determining Students' Ability to Interpret External Representations in Biochemistry. Int. J. Sci. Educ. 2009, 31, 193-232. [CrossRef]

32. Chi, M.T.H.; Feltovich, P.J.; Glaser, R. Categorization and Representation of Physics Problems by Experts and Novices. Cognit. Sci. 1981, 5, 121-152. [CrossRef]

33. Hmelo-Silver, C.E.; Marathe, S.; Liu, L. Fish Swim, Rocks Sit, and Lungs Breathe: Expert-Novice Understanding of Complex Systems. J. Learn. Sci. 2007, 16, 307-331. [CrossRef]

34. Thörne, K.; Gericke, N.; Hagberg, M. Linguistic Challenges in Mendelian Genetics: Teachers' Talk in Action. Sci. Educ. 2013, 97, 695-722. [CrossRef]

35. Ainsworth, S. DeFT: A Conceptual Framework for Considering Learning with Multiple Representations. Learn. Instr. 2006, 16, 183-198. [CrossRef]

36. Adadan, E. Using Multiple Representations to Promote Grade 11 Students' Scientific Understanding of the Particle Theory of Matter. Res. Sci. Educ. 2013, 43, 1079-1105. [CrossRef]

37. Goldman, S.R. Learning in Complex Domains: When and Why Do Multiple Representations Help? Learn. Instr. 2003, 13, 239-244. [CrossRef] 
38. Gericke, N.; Hagberg, M.; Doris, J. Upper Secondary Students' Understanding of the Use of Multiple Models in Biology Textbooks-The Importance of Conceptual Variation and Incommensurability. Res. Sci. Edu. 2012, 43, 755-780. [CrossRef]

39. Sherman, F. Getting Started with Yeast. Methods Enzymol. 1991, 194, 3-21. [CrossRef] [PubMed]

(C) 2018 by the authors. Licensee MDPI, Basel, Switzerland. This article is an open access article distributed under the terms and conditions of the Creative Commons Attribution (CC BY) license (http:/ / creativecommons.org/licenses/by/4.0/). 